\title{
Function words in rhythmic optimisation
}

\author{
Ralf Vogel, Ruben van de Vijver, \\ Sonja Kotz, Anna Kutscher, Petra Wagner \\ - draft version - \\ published in Ralf Vogel, Ruben van de Vijver (eds.), 2015, \\ Rhythm in Cognition and Grammar. A Germanic Perspective, \\ p. 253 - 274, Berlin: de Gruyter.
}

May 26, 2015 
The complex interplay between rhythm and word order has only rarely been addressed in linguistics. For many scholars, it might even be questionable, whether there is any interaction. Following Hayes (1995), we assume that the rhythmic flow of a sentence depends on the equal distribution of stressed and unstressed syllables and we will argue that the spoken form of a sentence depends, among other factors, on rhythm. Furthermore, we will present evidence that rhythmic principles govern word order in speech which leads to the proposal that rhythm is a syntactic constraint.

We will present three case studies, one concerning pronouns, one concerning auxiliary verbs and one concerning prepositional adverbs in German with which we explore several aspects of this claim. In particular, we will show that function words play a crucial role in the organisation of the rhythmic flow in speech. It affects their phonetic shape as well as their syntactic position.

Linguistic rhythm is manifested by the regular succession of stressed and unstressed syllables (Liberman \& Prince, 1977). The location of main stress in a word is lexically determined in German, but there are some common and predictable trends and stress is thus part of the word's phonology (Kiparsky, 1966; Wiese, 1996; Féry, 2000; Hall, 2000). The lexicon is quite heterogeneous in this respect: lexical items may vary in number of syllables as well as in the location of word stress. Therefore, rhythmic regularity is never automatically given for a sentence by just concatenating words. If rhythmic regularity is actively sought after, it has to be produced on the fly for every sentence or utterance.

The rhythm in a phonological phrase may be adjusted in two ways, both of which result in an even distribution of stressed and unstressed syllables (Prince, 1983; Nespor \& Vogel, 1986; Halle \& Vergnaud, 1987; Selkirk, 1984; Hayes, 1995). In one case a syllable which is weakly stressed is given a stronger stress under embedding, and in the other case a syllable which is strongly stressed is given a weaker stress under embedding. Often, the two processes occur in combination. A typical example is the German phrase "Úniversität Pòtsdam", in which Universität is stressed on the first syllable whereas it would be stressed on the last syllable in isolation (with the first syllable receiving secondary stress).

These processes do not influence the word order, though. An example of a rhythmic word order change comes from English and has been given by 
Bolinger (1965) in his discussion of the apparently irregular determiner placement in phrases such as "quite a long report" where $a$ serves as a buffer to avoid a stress clash - an obvious case of a rhythmic constraint overriding a syntactic constraint on word order.

A further means to achieve rhythmic regularity is by reduction or strengthening of words. Languages make a fundamental distinction between content words and function words with respect to stress and the phonetic flexibility to bear stress. Content words have one obligatory stress, whereas function words can be realised with and without stress. Function words are also much more prone to reduction than content words. Content words are overall more rigid in their realisation (which improves their recognition) while function words are more flexible. Because of their high frequency and salience, function words are easier to recognise even under strong reduction.

Are such effects of rhythm limited to phonological effects of realisation of stresses or are they more pervasive and influence the syntax of function words as well? While the former position is the traditional point of view, we think that it needs to be revised: rhythm is more important to syntax than linguists usually think.

The proposals that we will pursue in this paper are (i) that rhythmic optimisation is a pervasive feature of natural language and (ii) that the phonetic and prosodic, as well as the syntactic flexibility of function words is used to improve rhythmic regularity. Our experimental studies show that such phonetic or syntactic adjustments of function words occur systematically under particular metrical conditions.

\section{Variation in the perceived prominence of function words}

The first study that we present is an exploration of the "Bonner prosodische Datenbank" (Bonn prosodic database, BPD, Heuft 1999). The BPD is a database of spoken German. It contains a number of stories which have been read by experienced speakers. The 10661 syllables of the corpus have been annotated for perceptual prominence by three trained annotators (all phoneticians) on a scale of 0 (least prominent) to 31 (most prominent). The correlation between the annotators is good (Spearman $\rho$ ranges between 0.72 and 
0.82, with an average of 0.78 , Wagner 2000).

We compared the annotated prominence values for different word classes. If our assumption about the flexibility of function words is correct, then they should show a broader range of variation in prominence than content words.

For each syllable, the median of the three annotators has been used. We then calculated the variation coefficient by dividing the standard deviation by the mean. As the standard deviation is a measure of the spread around the mean, a variation coefficient close to one shows that the mean and its deviation are the same - there is great variation. The results are given in table 1 .

\begin{tabular}{l|c|c|c|c} 
& mean prom. & st. dev. & $\mathrm{n}$ & var coeff. \\
\hline determiner & 7.3 & 5.9 & 637 & .81 .0 \\
conjunction & 14.9 & 6.4 & 86 & .43 .0 \\
pronoun & 18.4 & 7.3 & 299 & .40 .0 \\
auxiliary & 14.6 & 5.0 & 143 & .34 .0 \\
modal verb & 16.0 & 4.2 & 113 & .26 .0 \\
negation & 20.3 & 5.0 & 152 & .25 .0 \\
noun & 21.9 & 5.0 & 958 & .23 .0 \\
proper name & 22.3 & 4.6 & 84 & .21 .0 \\
verb & 20.5 & 3.0 & 503 & .15 .0
\end{tabular}

Table 1. Perceptual prominence of different word classes in the BPD

The word classes are ordered by their variation coefficient in the final column. As expected, content words have an overall higher prominence, as the mean prominence values in the second column show. The standard deviation for the verbs, nouns and proper names is lower than for most function words, but the mean prominence of content words is much higher. The variation coefficients make this effect visible. Our expectation that the variation in prominence for the function words is higher is thus met by these corpus data.

However, the study tells us nothing about the contexts in which function words are stressed or reduced (and to what extent). In the next section we examine the hypothesis that one determining factor is metrical structure. 


\section{Metrically triggered pronoun strengthening and reduction}

According to Selkirk (1996), the English prosody makes a crucial distinction between content words and function words; only content words obligatorily bear lexical stress and, therefore, project prosodic words. Function words can occur in a strong, a weak and a reduced version. The strong version is a prosodic word that bears stress and has a full vowel. Weak versions of monosyllabic function words typically contain a reduced vowel and no longer form independent syllables but are incorporated in a neighbouring word.

Vogel (2006) has shown that Selkirk's description of English also applies to German and other Germanic languages. Germanic function words are an instructive example of the interplay of syntactic and prosodic constraints.

We conducted a sentence repetition task to study the distribution of the different realisations of pronouns in German. Our study focuses on the German neuter personal pronoun es ("it"). The pronoun has three forms:

\begin{tabular}{ccc}
\hline strong & weak & reduced \\
\hline$[\varepsilon s]$ & {$[\partial \mathrm{s}]$} & {$[\mathrm{s}]$}
\end{tabular}

Table 2. Three possible phonetic forms of the German pronoun es

The default distribution of weak and strong form seems to be that the weak form is preferred, but the strong form can be triggered by a particular context. ${ }^{1}$ One hypothesis that we test here is that strong(er) forms should be preferred clause-internally in metrically strong positions. Furthermore, the reduced variants should be preferred where they help to improve rhythmic regularity.

For our repetition experiment, we constructed three sets of 5 stimulus sentences each where es occurs in three metrically different positions. Examples are given in (1). The syllables in strong positions are boldfaced:

a. Ludwig nahm es mit nach Hause, um sich später drum Ludwig took it with to home for SELF later about-it zu kümmern

to care

"Ludwig took it home with him in order to deal with it later" 


\section{b. Martin hatte es versprochen, dass er Blumen gießen wird. Martin had it promised that he flowers water will "Martin had promised that he will water flowers." \\ c. Heinrich hat es verpasst, die Beute zu verstecken. Heinrich has it missed the haul to hide "Heinrich forgot to hide the haul."}

The 15 test sentences differed in their lexical material. We used no minimal pairs in order to avoid effects of repetition. The sentences for each of the three experimental condition shared a common rhythmical pattern within which the position of es was held constant. Condition 1, as in (1-a), provided a context for the weak form of the pronoun: stimulus sentences consisted of eight trochaic sequences with es in the weak position of the second sequence. Condition 2, as in (1-b), again contained eight trochaic sequences, this time es was in the strong position of the third sequence. Condition 3 , as in (1-c), should trigger the reduced version of es. We here have a pattern with six trochaic sequences where es occurs in the weak position of the second sequence, but this time it is followed by another schwa syllable in the unstressed prefix of the following verb. This makes the whole structure dysrhythmic; if es is unstressed there is a dysrhythmical string of two unstressed syllables and if it is stressed there is a dysrhythmical string of two stressed syllables. The realisation of $e s$ as strong, weak or reduced should follow from the ensuing rhythmicality.

The 22 participants of the experiment ( 8 men, 14 women) all had an academic background, most of them were students of the University of Bielefeld. Most participants come from the region around Bielefeld or Northern Germany. They were aged between 20 and 40 and had normal or corrected vision.

The participants were sitting in front of a computer. Each sentence was presented in written form for $3000 \mathrm{~ms}$ on the computer screen. After that the sentence disappeared and a symbol occurred on the screen to prompt the subjects to orally repeat the sentence they had just read. The experiment material was mixed randomly with 18 non-related filler sentences. In addition to the filler sentences, the repetition task was mixed with a visual memory task the 16 trials of which were interleaved with the experimental and filler trials.

The productions were recorded and analysed with Praat (Boersma \& Weenink, 2012). Overall, there were $22 \times 15=330$ trials. 10 of them had to be ex- 
cluded due to mistakes made by the subjects. In six of the remaining 320 trials the pronoun was omitted ( 3 in the reduction context, 2 in the context for the weak form, 1 in the context for the strong form). These have been excluded in the statistical analysis as well, since they provide no information about the influence of rhythm on the realisation of a pronoun as strong, weak or reduced.

The distinction in example (2) looks categorical, but from a phonetic perspective, the three versions of es should rather be seen as particular points on a continuous scale. For this reason, we make relational predictions, but remain agnostic about the precise phonetic correlates of the three "categories".

We use word length as measure, because it is known to be a reliable criterion for our purpose: vowel quality corresponds with vowel duration, and likewise stressed syllables tend to be longer than unstressed syllables (Ladefoged \& Johnson, 2010). We therefore predict that the pronoun should be longest in condition 2, where it is in a metrically prominent position, and shortest in condition 3 where reduction improves rhythmicality. This could be confirmed. The means of the three conditions are given in table 3 .

\begin{tabular}{lccc}
\hline & $\begin{array}{c}\text { strong } \\
\text { position (SP) }\end{array}$ & $\begin{array}{c}\text { weak } \\
\text { position (WP) }\end{array}$ & $\begin{array}{c}\text { reduction } \\
\text { position (RP) }\end{array}$ \\
\hline mean length in ms & 146.4 & 121.4 & 114.3 \\
stand. dev. & 29.2 & 24.3 & 18.9 \\
var. coeff. & .20 & .20 & .17 \\
$\mathrm{n}$ (324) & 102 & 106 & 106 \\
\hline
\end{tabular}

Table 3. mean length of $e s$ in strong, weak and reduction position, calculated over all 314 trials

We tested the results for significance using t-tests. All contrasts were significant in a by-trial analysis. The results of the analyses are given in (2).

(2) Results of t-tests on a by-trial basis:

$$
\begin{array}{ll}
\mathrm{SP} \sim \mathrm{WP}: & \mathrm{t}=6.6834, \mathrm{df}=194.907, \mathrm{p}<.001 \\
\mathrm{SP} \sim \mathrm{RP}: & \mathrm{t}=9.3212, \mathrm{df}=169.99, \mathrm{p}<.001 \\
\mathrm{WP} \sim \mathrm{RP}: & \mathrm{t}=2.3693, \mathrm{df}=199.785, \mathrm{p}=0.01877
\end{array}
$$


Additional by-subject and by-item analyses were conducted to verify this result and check for subject- or item-related effects. In the by-subject analysis the same significance levels are reached as in (2). In the by-item analysis the only difference is that the t-test for $\mathrm{WP} \sim \mathrm{RP}$ is no longer significant. This is due to higher heterogeneity of the stimulus material for the WP condition as compared to both the SP and the RP condition. In table 4, the means, standard deviations and variation coefficients for the three conditions are given on a by-item basis where for each individual item the median of the (at most) 22 trials is used:

\begin{tabular}{lccc}
\hline & $\begin{array}{c}\text { strong } \\
\text { position (SP) }\end{array}$ & $\begin{array}{c}\text { weak } \\
\text { position (WP) }\end{array}$ & $\begin{array}{c}\text { reduction } \\
\text { position (RP) }\end{array}$ \\
\hline mean length in ms & 147.4 & 122.5 & 111.6 \\
stand. dev. & 10.6 & 14.9 & 3.7 \\
var. coeff. & .07 & .12 & .03 \\
n (15) & 5 & 5 & 5
\end{tabular}

Table 4. Mean length of es in strong, weak and reduction position, calculated by item based on each item's median

We see that the variation coefficient for WP is four times higher than for the $\mathrm{RP}$ condition where it is very low.

Though this study is not perfect methodologically, as just illustrated, it provides some insights. It is, first of all, an important finding that the pronoun is significantly longer in the SP context. Together with the study in the previous section, this experiment confirms our assumptions about the role of function words in rhythmic optimisation. We have clear evidence here that rhythmic optimisation takes place in speech. If this were not the case, then it could not be explained why the length of the pronoun varies so systematically with the metrical context. There would be no need for reduction in the RP context or for strengthening in the SP context if rhythmic regularity was not an issue.

The studies that we present in the following sections seek for word order effects of rhythmic optimisation. 


\section{Order preferences in German 3-verb clusters}

The German verb phrase is a very interesting example of variation, optionality and gradience in syntax. Depending on number and type of the verbs involved, a verbal complex may underlie different restrictions. Accounting for this in a uniquely syntactical approach is a difficult issue. ${ }^{2}$ A popular topic in this respect are verbal complexes that consist of three verbs. As Schmid (2005) shows, such complexes are quite frequent in the West Germanic languages and dialects, and their syntax varies in an interesting and systematic way.

The 3-verb complexes that are studied best consist of a temporal auxiliary, a modal, causative or perception verb, and a lexical verb. The verbs in such a complex are conventionally labelled as $\mathrm{V}_{1}, \mathrm{~V}_{2}$ and $\mathrm{V}_{3}$, respectively. German is a verb-final language with the finite verb in second position in main clauses. Subordinate clauses are usually verb-final, and it is the order and morphological form of such sentence-final complexes that is usually focused on:

$$
\begin{aligned}
& \text { weil er Lieder singen können wird } \\
& \text { because he songs sing- } \mathrm{V}_{3} \text {-INF can- } \mathrm{V}_{2} \text {-INF will- } \mathrm{V}_{1} \text {-INF } \\
& \text { "...because he will be able to sing songs." }
\end{aligned}
$$

The orders in the verbal complex that are found to be acceptable for Standard German are the following ones: ${ }^{3}$
a. 321 order: ... singen können wird.
b. 132 order: ... wird singen können.
c. 312 order: ... singen wird können.

In a corpus study on the corpus of the Institut für deutsche Sprache (IDS) Mannheim, ${ }^{4}$ we found among 500 randomly selected instances of sentence final verb clusters 326 instances of the 132 order and 51 with the 312 order. Whereas the 132 order was found in newspapers from Germany, Switzerland and Austria, all instances of the 312 order were from Austrian or Swiss newspapers. There indeed seems to be a standard German bias against the 312 order which is weaker in the southern parts of the German speaking region. 
Prescriptive grammars sometimes label the 312 order as a Southern German variant. Bader \& Schmid (2009) show that speakers from all German speaking regions give the 312 order a high acceptability rating, though not as high as for the 132 order.

In addition to that, the dialect has a higher prestige in the southern regions than in middle and northern Germany. Both Switzerland and Austria have their own variants of Standard German which include some aspects of the local dialect families. Authors from these regions might therefore have less reservations against using the 312 order in written language.

Here we are interested in verb clusters in the perfect tense. These have a further restriction: modal verbs used as $\mathrm{V}_{2}$ may not be realised as participles and the 321 order (which seems to require the participle in the $V_{2}$ position) is excluded. The modal verb instead has to be realised as infinitive in the 132 or 312 orders, where 132 order is again preferred:

$$
\begin{aligned}
& \text {... weil er es... } \\
& \text { because he it } \\
& \text { a. *... } \begin{array}{l}
\text { singen gekonnt hat. (321 order) } \\
\text { sing can-PRTCPL has }
\end{array} \\
& \text { b. } \quad \text {.. } \begin{array}{l}
\text { hat singen können (132 order) } \\
\text { has sing can-INF }
\end{array} \\
& \text { c. } \quad \text {... } \begin{array}{l}
\text { singen hat können (312 order) } \\
\text { sing has can-INF }
\end{array}
\end{aligned}
$$

The question that we focused on in two experimental studies is whether the choice for the 132 or 312 order can be influenced by rhythm. One possible generalisation about the three options for Standard German in (4) or the two in (5) is that it is only the position of the auxiliary that is variable, whereas that of the other elements is fixed. If this is the case, and we have optionality here, then it might be that speakers choose the rhythmically optimal position for the auxiliary.

The material for the experiments to be reported in this section consisted of two kinds of patterns, a rhythmic one and a dysrhythmic one. In both patterns the material that we used is based on a dactylic pattern (one stressed syllable followed by two unstressed ones). We constructed sentences that differ min- 
imally in the lexical verb. Two different types of prefixed trisyllabic verbs serve our purpose. The first type has stress on the prefix and the second type on the stem as in the following examples:

(6) a. Verbs with stress on prefix: einschlafen ('fall asleep'), zugreifen ('grip'), aufräumen ('tidy (up)')

b. Verbs with stress on stem: erfrieren ('freeze to death'), entfliehen ('escape'), verlieren ('lose')

The sentences consist of a main clause with a pronominal subject and a verb of saying or believing, complemented by a subordinate clause introduced with the complementizer dass ('that'). The complementizer is followed by a proper name (two syllables, stress on first syllable) as subject, introduced by a determiner. After the subject comes a verbal complex in 132 or 312 order with the third person form of the auxiliary haben, a modal verb and a prefixed intransitive lexical verb which has stress on either the prefix or the stem. As a consequence, the 312 order has a regular dactylic pattern with stem stressed verbs, and the 132 order with prefix stressed verbs:

(7) Regular pattern:

a. Er glaubt dass der Benno hat einschlafen müssen. he thinks that the Benno has fall-asleep-INF must-INF "He thinks that Benno had to fall asleep."

(132 order)

b. Sie meint dass die Laura erfrieren hat können.

She thinks that the Laura freeze-to-death-INF has can-INF "She thinks that Laura could have frozen to death." (312 order)

(8) Dysrhythmic pattern:

a. Er glaubt dass der Benno einschlafen hat müssen. (312 order)

b. Sie meint dass die Laura hat erfrieren können. (132 order) 


\subsection{Rhythmic regularity and acceptability}

The first experiment was a pilot study for the production experiment that we report below. It was carried out as a speeded grammaticality judgment task. For each of the four conditions illustrated in (7) and (8) we prepared eight lexical variants. The 32 test sentences were mixed with 24 related ungrammatical filler sentences and 168 non-related sentences. ${ }^{5}$ The material was recorded for auditory stimulus presentation by a phonetically trained speaker who was instructed to let the material sound naturally. The participants of the experiment were 21 students of the university of Potsdam. The test sentences were presented over ear phones at a comfortable listening level. After presentation of each stimulus, the participants were requested to give their acceptability judgment by pressing one of two buttons for "grammatical"/"ungrammatical". Table 5 presents the results.

\begin{tabular}{l|cc}
\hline & V: stress on prefix & V: stress on stem \\
\hline 132 order - AuxVMod & 86.3 & 86.1 \\
\hline 312 order - VAuxMod & 74.9 & 73.0 \\
\hline
\end{tabular}

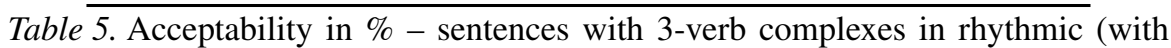
frame) and dysrhythmic conditions

The experiment replicates earlier findings about the lower but still high acceptability of the 312 order. Apart from this syntactic effect, no effect of rhythmicity could be detected. This can be explained straightforwardly. First of all, the stimuli have all been recorded such that they sound naturally. The speaker therefore might already have adjusted the dysrhythmic material by the phonetic means illustrated in the previous section so that there was not much of a difference in rhythmicality in the material.

Second, subjects have not been explicitly instructed to judge rhythmic wellformedness. They were only asked to judge the acceptability of the sentences. It is very likely that they therefore used some standard idea of linguistic acceptability in which rhythm plays no role at all. Hence, when subjects are asked to give a wellformedness statement for a given sentence, they might check for correct inflection, word order and other grammatical properties, but not for rhythm or other non-obvious phonological aspects. Both of these explanations are plausible and to our minds highly probable. 
We can conclude that the acceptability judgment experiment is an inappropriate method to test the interaction of rhythmic and grammatical constraints. This is perhaps not surprising. It is difficult even to produce acoustic stimuli that contain rhythmic errors in a natural and controlled way and it is also difficult to perceive such errors because speakers tend to correct them unconsciously.

\subsection{Rhythmic regularity in production}

We decided to shift from perception to production based methods. The design of the second experiment is inspired by McDonald et al. (1993) who used a recall task to simulate language production. They elicited word order effects of a similar kind as in our case.

The stimuli had the same structure as before. There were again eight lexical variants of the four conditions in (7) and (8) which have been recorded by a phonetically trained speaker. The stimuli were presented to the participants over ear phones at a comfortable listening level. The material was randomly mixed with 32 fillers, the items of another experiment that we discuss in the following section.

After stimulus presentation, the subjects were prompted to reproduce the sentence they just had heard. The answers were recorded and analysed. 22 subjects took part in this experiment, all of them students of the university of Leipzig. The experiment was carried out at the Max-Planck Institute for Cognitive Neuroscience, Leipzig. The experiment is described and analysed in detail in Imhof (2007). ${ }^{6}$

Unlike acceptability judgments, the method used here only indirectly targets the linguistic competence of speakers. Successful recall may depend on various factors: the difficulty of the task, memory capabilities, as well as the linguistic factors we are looking for. When subjects make errors in recalling the stimulus, however, we assume that their output is guided by linguistic principles. Hence, only the errors that subjects make are informative for our purposes. If the errors are not evenly distributed among the four conditions, then this should be due to the linguistic factors that differentiate them. A significantly different distribution of errors among the four conditions is 
therefore evidence for the relevance of these factors to grammar.

We were particularly interested in incorrect reproductions of the word order in the verbal complex. We have two hypotheses concerning the outcome of the experiment. One is that the syntactic preference for the 132 order should lead to more errors in the two conditions with the 312 order. The second hypothesis is that there should be more errors in the dysrhythmic conditions due to word order changes to achieve regular rhythm. Table 6 displays the error rates for the four conditions. An error means here that a 312 order has been reproduced as 132 order and vice versa. The figures for the two rhythmic conditions are again framed.

\begin{tabular}{l|cc}
\hline & V: stress on prefix & V: stress on stem \\
\hline 132 order - AuxVMod & 0.0 & 2.8 \\
\hline 312 order - VAuxMod & 54.9 & 17.6 \\
\hline
\end{tabular}

Table 6. Reproduction errors in the verbal complex in \% in Experiment 2

Both factors have an influence on reproduction errors. The conditions with 132 order have been reproduced with low error rate, even in the dysrhythmic condition. For the 312 order, we see a very high error rate for the dysrhythmic condition. More than half of the items in this condition have been reproduced with 132 order. For the condition with 312 order and regular rhythm, the error rate is less than half.

We carried out two two-factorial repeated measures ANOVAs with the random factors ITEM and SUBJECT, respectively. The factors that we tested - including their interaction - are WORD ORDER (Syn) and RHYTHMIC REGULARITY (Rhy) with two levels each. The dependent variable are the reproduction errors in \%. Table 7 displays the results. We see that both factors as well as their interaction were highly significant in the analyses for both random factors.

Further examination reveals that the significance of the factor rhythm is due to the high contrast between the two conditions with 312 order. The contrast between the conditions with 132 order is only marginally significant (see table 8).

The dysrhythmic condition with 312 order points to a difficulty that we al- 


\begin{tabular}{|c|c|c|c|}
\hline $\mathrm{F} 1(\mathrm{Syn}, \mathrm{df}=1)$ & F2 (Item, $\mathrm{df}=7)$ & $F=468.3$ & $\mathrm{p}<.001$ \\
\hline F1 (Rhy, df = 1) & $\mathrm{F} 2($ Item, $\mathrm{df}=7)$ & $F=43.797$ & $\mathrm{p}<.001$ \\
\hline F1 $($ Syn $\times$ Rhy, df $=1)$ & F2 (Item, $\mathrm{df}=7)$ & $F=48.017$ & $\mathrm{p}<.001$ \\
\hline $\mathrm{F} 1(\mathrm{Syn}, \mathrm{df}=1)$ & F2 (Subjects, df $=21)$ & 31.578 & .001 \\
\hline F1 (Rhy, df = 1) & F2 (Subjects, df $=21)$ & $\mathrm{F}=27.361$ & $\mathrm{p}<.001$ \\
\hline F1 $($ Syn $\times$ Rhy, df $=1)$ & $\mathrm{F} 2($ Subjects, $\mathrm{df}=21)$ & $\mathrm{F}=21.159$ & $\mathrm{p}<.001$ \\
\hline
\end{tabular}

Table 7. Results of ANOVAS by Item and by Subjects, production experiment on verb clusters

\begin{tabular}{lll}
132 (rh.) $\sim$ & $\mathrm{t}=-2.0174, \mathrm{df}=21, \mathrm{p}=0.056$ & $\begin{array}{l}\text { (by subject) } \\
\text { (by item) }\end{array}$ \\
\hline 32 (dysrh.) & $\mathrm{t}=1.9296, \mathrm{df}=7, \mathrm{p}=0.095$ & $($ o \\
\hline 312 (rh.) $\sim$ & $\mathrm{t}=1.9296, \mathrm{df}=7, \mathrm{p}<.001$ & $* * *$ (by subject) \\
312 (dysrh.) & $\mathrm{t}=8.4125, \mathrm{df}=11.06, \mathrm{p}<.001$ & $* * *$ (by item)
\end{tabular}

Table 8. t-tests within 132 and 312 orders

ready mentioned above. We have a distribution with two peaks at the extremes: seven participants made no or one word order error whereas the other participants made at least four errors in this condition. These seven also made no or only one word order error overall. The other participants made at least six errors.

This outcome is easy to explain. Independently of their linguistic capabilities, participants perform well in this experiment if they are good memorisers. But this also means that those subjects confound the linguistic effects that we are intrerested in. When we exclude the seven excellent memorisers, the picture gets even clearer, as table 9 shows.

\begin{tabular}{l|cc}
\hline & V: stress on prefix & V: stress on stem \\
\hline 132 order - AuxVMod & 0.0 & 4.2 \\
\hline 312 order - VAuxMod & 79.0 & 25.0 \\
\hline
\end{tabular}

Table 9. Reproduction errors in the verbal complex in \% in Experiment 2, without excellent memorisers

In particular, we now have an error rate of nearly $80 \%$ for the dysrhythmic 
312 order, and only $25 \%$ for the rhythmic 312 order. This result justifies a strong claim, namely that the 312 order - contrary to the 132 order - is avoided in spontaneous speech, if it is rhythmically disadvantageous. In other words: rhythm is crucial for word order in spontaneous speech, and therefore should be considered a syntactic constraint.

\subsection{Acoustic Analyses}

Following our observations on the different phonetic properties of function words in different metrical positions, we expect length effects in the four different conditions. We analysed the productions of a randomly chosen subject whose productions showed no errors or hesitations.

Figures 1 and 2 display the average syllable lengths for the two conditions with 312 order in the verbal complex. In figure 1, we see a pattern of three clearly identifiable dactylic feet. Leaving out the initial unstressed syllable (here and throughout), each foot starts with a stressed syllable that is much longer than the two following syllables. The final foot should also form a dactylic foot, but the expected pattern for such a foot is confounded by final lengthening, a well-known feature of sentential prosody (Cambier-Langeveld, 2000).

The syllable lengths of the dysrhythmic stimuli with 312 order are displayed in figure 2 . The three dactylic feet are clearly recognisable and final lengthening can also again be detected as the peaks in the duration line in 1 . The third foot is remarkable as it shows a stress shift: the particle verbs used in this condition such as "einladen" have their word stress on the particle. However, in this case, the first syllable of the verbal stem is longer than the syllable of the particle. We observe thus a stress shift that is induced by the need to maintain a regular dactylic rhythm.

ce

In a further analysis, we examined the length of the auxiliary "hat" in the four conditions, as measured in the stimulus items. The results are summarised in table 10 .

The auxiliary has equal length in the two conditions with 132 order. However, 


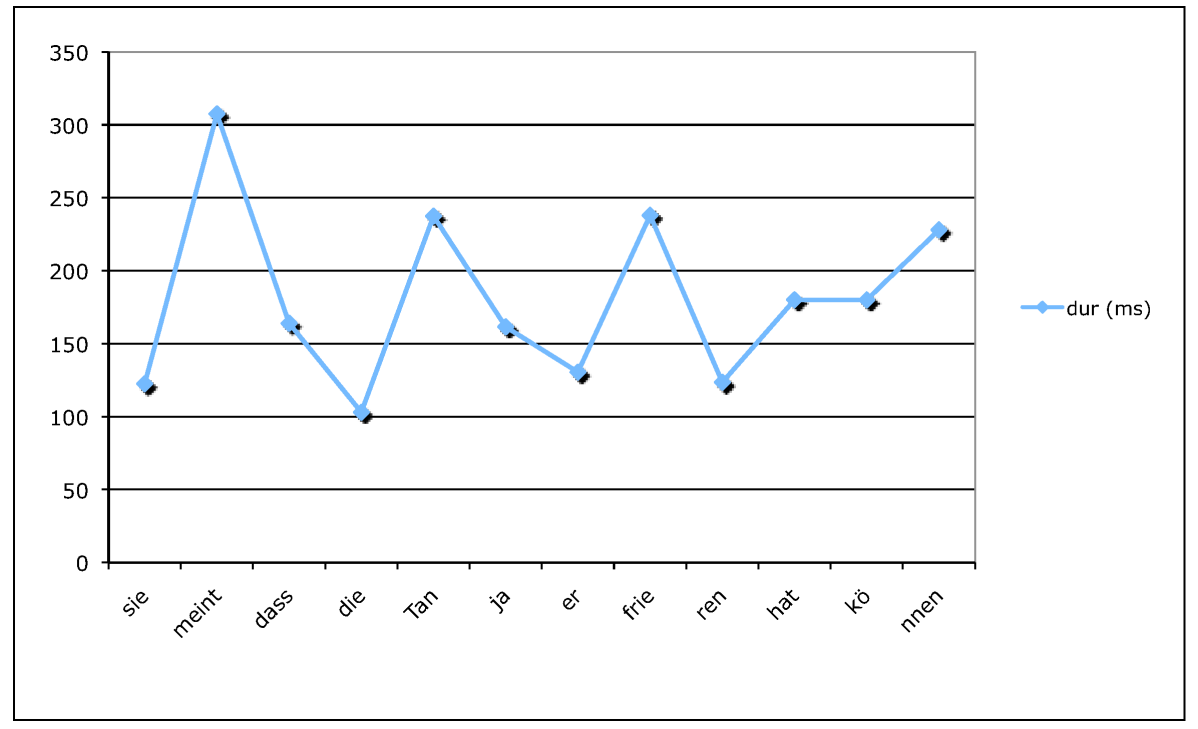

Figure 1. Regular rhythmical pattern is kept constant throughout utterance. Data of 1 speaker, means of 8 sentences.

\begin{tabular}{l|ccc}
\hline & mean length (ms) & stand. dev. & var.coeff. \\
\hline 132 order, rhythmic & 144 & 19 & .13 \\
132 order, dysrhythmnic & 141 & 31 & .22 \\
312 order, dysrhythmic & 130 & 32 & .25 \\
312 order, rhythmic & 191 & 16 & .09
\end{tabular}

Table 10. Average durations for the auxiliary "hat" in the stimulus sentences of the four conditions

we have a much higher standard deviation in the dysrhythmic condition that also leads to a higher variation coefficient. The same can be observed in the verbal complexes with 312 order. In the 312 order, the auxiliary is closer to the end of the clause. Because of final lengthening, we expect the auxiliary to be longer than in the 132 order. This is only borne out in the rhythmic 312 order. In the dysrhythmic 312 condition, the auxiliary has the shortest duration of all four conditions. This can be explained as a compensatory reduction triggered by the stress shift on the preceding particle verb that we observed for this condition. ${ }^{7}$ 


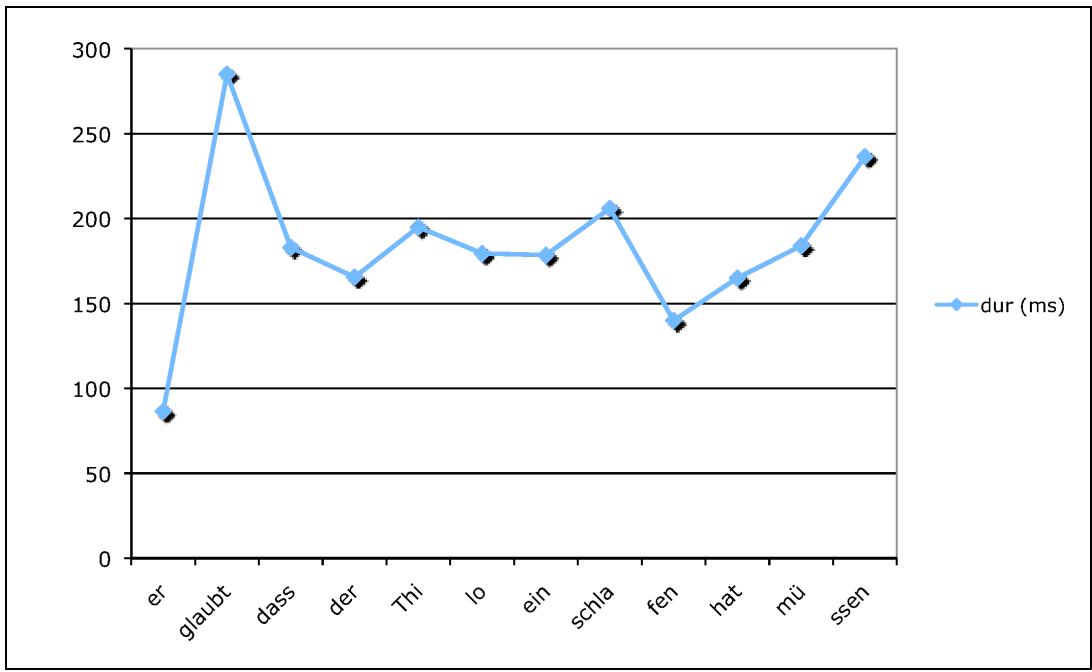

Figure 2. Regular rhythmical pattern is upheld via stress shift on neighboring syllable. Data of 1 speaker, means of 8 sentences .

\section{Order preferences with pronominal adverbs}

The next experiment focuses on a special kind of German function words, so called pronominal adverbs (PA). PAs are typical of colloquial language and widely distributed among German dialects. ${ }^{8}$ PAs can occur optionally to double prepositions:

(9) Ich sitze auf dem Stuhl (drauf).

I sit on the chair PA

Morphologically, the PA in (9) contains two elements: "dr-", a short version of "da(r)" ( 'there') plus the preposition which is copied from the PP. We have a reduced form of the PA in (9). ${ }^{9}$ The full form can be used as pro-form replacing a PP:

(10) Ich sitze darauf. 
When the PP is fronted, we have two options for replacement with pronominal PPs, either full movement, or a structure that has - perhaps mistakenly been called a PP split construction:
a. Darauf sitze ich
PA-full sit I
b. Da sitze ich drauf
There sit I PA-reduced

\subsection{The production experiment}

The structure in (11-b) is the one that we used in our experiment. Note that contrary to (9), the reduced PA is obligatory in (11-b), as the preposition surfaces only in the PA. For the experiment, we constructed sentences which again use a dactylic pattern. The position of the PA varies minimally relative to a trisyllabic indefinite plural noun which is stressed either on first (e.g., "Kohlrüben", 'rutabagas') or on second syllable (e.g., "Tomaten", 'tomatoes').

(12) Experiment conditions, PA $<$ noun order:

a. Da wollte der Peter Tomaten drin kochen (rhythmic) there wanted the Peter tomatoes PA-in cook

b. Da wollte der Peter Kohlrüben drin kochen there wanted the Peter rutabagas PA-in cook (dysrhythmic)

Experiment conditions, noun $<$ PA order:
a. Da wollte der Peter drin Tomaten kochen (dysrhythmic) there wanted the Peter PA-in tomatoes cook
b. Da wollte der Peter drin Kohlrüben kochen (rhythmic) there wanted the Peter PA-in rutabagas cook

The experiment was a filler experiment for the production experiment with verbal complexes that we discussed in the previous section. Method and par- 
ticipants were the same.

As in the previous experiment, we predict that the dysrhythmic pattern should be more prone to recall errors in word order than the rhythmic patterns.

Is there also a syntactic preference? In principle, there should be. The PAs in the experiment all function as adverbials in their clauses. Their natural syntactic position is therefore adjunction to the verb phrase, whereas the indefinite plural nouns - serving as direct objects - should have their default position within VP. Thus, there should be a syntactic preference for the $\mathrm{PA}<$ noun order. But it is certainly relatively weak, given the opportunities to arrange constituents quite freely in German clauses.

A further issue is the question whether the effects should be as large as we found them with auxiliaries. Whereas auxiliaries serve a purely grammatical function, much like pronouns and determiners, PAs, like prepositions and also modal verbs, are somewhat between function words and content words. They represent closed classes with a small fixed inventory, show reduction systematically, but they still have semantic content. Participants in the experiment should therefore pay more attention to the PAs than to the auxiliaries and this should lead to a greater overall accuracy. This expectation is met, as can be seen in Table 11 which lists results of the experiment. The rhythmic conditions are again framed.

\begin{tabular}{c|cc}
\hline & noun: stress on $1^{\text {st }}$ syll. & noun: stress on $2^{\text {nd }}$ syll. \\
\hline PA $<$ noun order & 6.3 & 9.7 \\
\hline noun $<$ PA order & 8.5 & 2.3 \\
\hline \hline
\end{tabular}

Table 11. Rhythmic and dysrhythmic sentences with pronominal adverbs, recall errors in \%

The error rate for the dysrhythmic conditions is higher $(9.1 \%$ vs. $4.3 \%$ in the means), whereas the syntactic factor only seems to play a marginal role. The means are $8 \%$ for the PA-N order vs. $5.4 \%$ for the N-PA order. Thus, there even is a slightly higher error rate for the assumed syntactic preference.

We analysed the results in two two-factorial repeated measures ANOVAs with the random factors ITEM and SUBJECT, respectively. The factors we tested - including their interaction - were WORD ORDER (Syn) and RHYTHMIC 
REGULARITY (Rhy). The dependent variable again was the recall error rate.

In the item analysis, only the factor rhythm was significant $(\mathrm{df}=7, \mathrm{~F}=9.3465$, $\mathrm{p}=.018)$. It was marginally significant in the subjects analysis $(\mathrm{df}=21, \mathrm{~F}=4.0736$, $\mathrm{p}=.056$ ). Neither the syntactic factor nor the interaction of the two factors were significant (see table 12 for details). Excluding the excellent memorisers detected in the verb cluster experiment did not change this picture, as we already have a high overall accuracy.

\begin{tabular}{|c|c|c|c|}
\hline $\mathrm{F} 1(\mathrm{Syn}, \mathrm{df}=1)$ & F2 (Item, $\mathrm{df}=7$ ) & $\mathrm{F}=1.5897$ & $\mathrm{p}=.2478$ \\
\hline F1 (Rhy, df = 1) & F2 $($ Item, df $=7)$ & $F=9.3465$ & $\mathrm{p}=.0184$ \\
\hline F1 $($ Syn $\times$ Rhy, df $=1)$ & F2 $($ Item, $\mathrm{df}=7)$ & $\mathrm{F}=4.9964$ & $\mathrm{p}=.0605$ \\
\hline $\mathrm{F} 1(\mathrm{Syn}, \mathrm{df}=1)$ & $\mathrm{F} 2($ Subjects, $\mathrm{df}=21)$ & $\mathrm{F}=0.4084$ & $\mathrm{p}=.5297$ \\
\hline F1 (Rhy, df = 1) & $\mathrm{F} 2($ Subjects, $\mathrm{df}=21)$ & $\mathrm{F}=4.0736$ & $\mathrm{p}=.05651$ \\
\hline F1 $($ Syn $\times$ Rhy, df $=1)$ & F2 (Subjects, df $=21)$ & $\mathrm{F}=0.5153$ & $\mathrm{p}=.4808$ \\
\hline
\end{tabular}

Table 12. Results of ANOVAS by Item and by Subjects, production experiment on pronominal adverbs

The verb cluster experiment showed that this method is sensitive to both syntactic and rhythmic constraints, a well as their interaction. The lack of a syntactic effect in this experiment might therefore be evidence that there is no such syntactic preference here, or, that this constraint is much weaker than the rhythmic constraint, too weak to show an effect.

\subsection{Acoustic Analyses}

For the acoustic analysis of these data, we used the stimuli of the experiment which were recorded from one single speaker. Figure 3 displays the syllable lenghts in the condition with rhythmic $\mathrm{PA}<$ noun order. Again, the syllable lengths reflect a regular dactylic pattern. Word stress is as expected.

In figure 4, we see the dysrhythmic condition with $\mathrm{PA}<$ noun order. The syllable of the PA, "drin" in our example, is longer than its two neighbouring syllables. This is due to a kind of rhythmic repair that we have not yet discussed, namely, the shift to a different rhythm. The first foot is a dactyl, but from the fourth syllable on we have alternating longer and shorter syllables. 


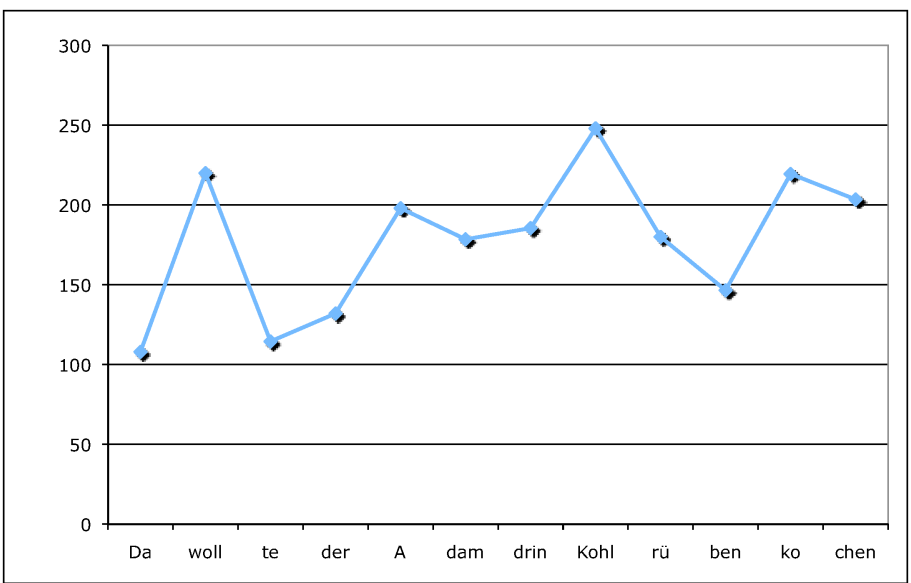

Figure 3. Unstressed pronominal adverb where the rhythm is continued by an unstressed adverb. (Data of one speaker, medians across 8 sentences)

Thus the speaker has shifted to a trochaic pattern which is then kept till the end of the sentence.

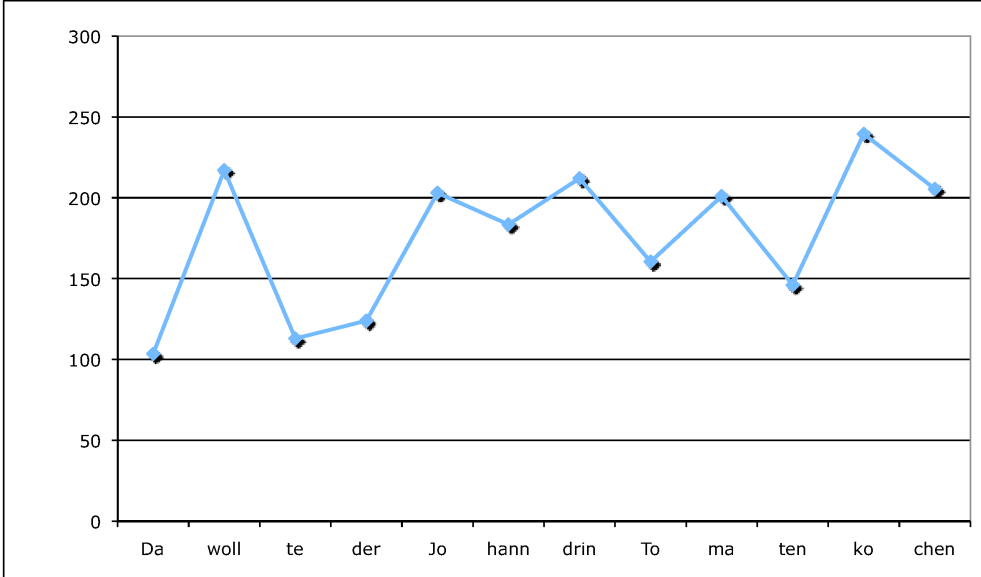

Figure 4. Stressed pronominal adverb where it fills a potential rhythmical gap. Initial rhythmical pattern is changed. 


\section{Conclusion}

In this chapter we explored the contribution of rhythm to syntactic wellformedness. In several perception and production experiments we showed that its contribution is small but notable. We first established that rhythm influences the realisation of pronouns. Pronouns are longer in positions where rhythm demands a stress and shorter in positions where rhythm demands a stressless syllable. They are shortest in contexts where non-syllabilicity improves rhythmic regularity. We then showed that the order of verbs in threeverb clusters is optional and that speakers and hearers base their preference for a specific order on rhythmic considerations.

Our chapter also makes a more methodological point. Syntax is influenced by factors that can only be experimentally determined. Rhythm plays a role, but it is a subtle one that can only be established by methodically studying the patterns that are involved. Furthermore, the factor is obviously too subtle to contribute to the kind of metalinguistic judgments typically used in acceptability experiments. This raises the issue of which data to trust more in empirical research on grammar. We here take the position argued for independently by others (cf. Devitt 2010 for a more recent proposal) that corpus data as well as data from production studies should be privileged as these are primary data. Judgments are metalinguistic intuitions about such primary data and therefore necessarily less direct evidence with a greater risk of confounding effects.

In general, then, we found that rhythm is one of the factors that governs word order. From a theoretical perspective this is interesting, because it suggests that phonological information is available for syntax at an early level of processing; a finding that has independently been established by Kentner (2012). 



\section{Chapter 1}

\section{Notes}

1. As Selkirk (1996) shows for English and Vogel (2006) for German the strong form is required at the right edge of phonological phrases. Wagner (2000) observed in addition that phrase-initial function words also have a higher prominence.

2. A non-exhaustive sample of references includes Wurmbrand (2006); Schmid (2005); Hinterhölzl (1999); Meurers (2000); Schmid \& Vogel (2004); Sapp (2006); Vogel (2009)

3. See Bader \& Schmid (2009) for a detailed empirical exploration of the possible orders in standard German.

4. The subcorpus "W-all" was used, which is a huge corpus of written German that mainly consists of German, Swiss and Austrian newspaper texts. As of May 2012, the corpus of written texts of the IDS has about 5.2 billion words and is the largest corpus of its kind world-wide, according to the official website. It is the largest linguistic corpus world wide. We conducted our corpus research using the Cosmas II search tool developed for corpus research on the IDS corpora.

5. The results for three misconstructed items were excluded.

6. The authors thank Ulrike Imhof for providing us with the data and results of the experiment for the analyses carried out in this section.

7. A $\chi^{2}$ test for the four variation coefficients was significant $\left(\chi^{2}=7.8165\right.$, $\mathrm{df}=1, \mathrm{p}=$ $0.005177)$. The $\mathrm{t}$-test for the auxiliary duration in the two conditions with 312 order was significant $(\mathrm{t}=4.6733, \mathrm{df}=10.49, \mathrm{p}=0.0007709)$.

8. See Fleischer (2002) for a detailed study on PAs in German dialects.

9. Reduced PAs of consonant-initial prepositions leave out "dr-", as e.g. for "mit" ("with'): "damit" (full PA) vs. "mit" (reduced PA). 



\section{Bibliography}

Bader, Markus \& Tanja Schmid (2009). 'Verb clusters in Colloquial German.' Jornal of Comparative Germanic Linguistics 12:175-228.

Boersma, Paul \& David Weenink (2012). 'Praat: Doing phonetics by computer (version 5.3.09) [computer program].' Tech. rep., Universiteit van Amsterdam.

URL: http://www .praat.org/

Bolinger, Dwight LeMerton (1965). 'Pitch Accent and Sentence Rhythm.' In: 'Forms of English: Accents, Morphemes, Order,' pp. 139-180. Harvard University Press, Cambridge, Mass.

Cambier-Langeveld, Tina (2000). Temporal Marking of Accents and Boundaries. Ph.D. thesis, Holland Institute of generative Linguistics.

Devitt, Michael (2010). 'What Intuitions are Linguistic Evidence?' Erkenntnis 73:251-264.

Féry, Caroline (2000). 'Phonologie des Deutschen: Eine optimalitätstheoretische Einfürung.' In: Hans-Martin Gärtner, Ruben van de Vijver, \& Christian Wartena (eds.), 'Linguistics in Potsdam,' vol. 7. Universitätsbibliothek, Publikationsstelle, Potsdam.

Fleischer, Jürg (2002). Die Syntax von Pronominaladverbien in den Dialekten des Deutschen: eine Untersuchung zu Preposition Stranding und verwandten Phänomenen. No. 123 in Zeitschrift für Dialektologie und Linguistik, Beihefte. Steiner, Stuttgart/Wiesbaden.

Hall, Tracy Alan (2000). Phonologie: Eine Einfürung. Mouton de Gruyter, Berlin.

Halle, M. \& J.R. Vergnaud (1987). An essay on stress. MIT Press.

Hayes, Bruce (1995). Metrical Stress Theory: Principles and Case Studies. University of Chicago Press, Chicago. 
Heuft, Barbara (1999). Eine prominenzbasierte Methode zur Prosodieanalyse und-synthese, vol. Sprache, Sprechen, Computer. Peter Lang, Frankfurt a. M. (also doctoral dissertation, Universität Bonn, Germany).

Hinterhölzl, Roland (1999). Restructuring infinitives and the theory of complementation. Ph.D. thesis, University of Southern California.

Imhof, Ulrike (2007). Experimentelle Studie zur Interaktion syntaktischer und metrischer Faktoren in der Sprachproduktion. Diplomarbeit, Institut für Linguistik, Universität Potsdam.

Kentner, G. (2012). 'Linguistic rhythm guides parsing decisions in written sentence comprehension.' Cognition 123:1-20.

Kiparsky, P. (1966). 'Über den deutschen Akzent.' studia grammatica 7:69_ 98.

Ladefoged, P. \& K. Johnson (2010). A course in phonetics. Wadsworth Pub Co.

Liberman, M. \& A. Prince (1977). 'On stress and linguistic rhythm.' Linguistic Inquiry 8(2):249-336.

McDonald, Janet L., Kathryn Bock, \& Michael H. Kelly (1993). 'Word and World Order: Semantic, Phonological and Metrical Determinants of Serial Position.' Cognitive Psychology 25:188-230.

Meurers, Walt Detmar (2000). Lexical Generalizations in the Syntax of German Non-Finite Constructions. Ph.D. thesis, Universit"at T"ubingen, T"ubingen. Arbeitspapiere des SFB 340, Bericht Nr. 145.

URL: http://www.sfs.uni-tuebingen.de/sfb/reports /berichte/145/145abs.html

Nespor, Marina \& Irene Vogel (1986). Prosodic Phonology. Foris, Dordrecht.

Prince, Alan S. (1983). 'Relating to the Grid.' Linguistic inquiry 14(1):19100.

URL: http://cat. inist.fr/?aModele=afficheN\&cpsidt $=11788142$

Sapp, Christoper D. (2006). Verb order in subordinate clauses from early new high German to modern German. Ph.D. thesis, Indiana University. 
Schmid, Tanja (2005). Infinitival syntax: Infinitivus Pro Participio as a repair strategy. John Benjamins, Amsterdam.

Schmid, Tanja \& Ralf Vogel (2004). 'Dialectal Variation in German 3-Verb Clusters. A Surface-Oriented Optimality Theoretic Account.' Journal of Comparative Germanic Linguistics 7:235-274.

Selkirk, E. (1984). Phonology and Syntax: The Relation between Sound and Structure. MIT Press, Cambridge, MA.

Selkirk, Elisabeth (1996). 'The Prosodic Structure of Function Words.' In: James L. Morgan \& Katherine Demuth (eds.), 'Signal to Syntax: Bootstrapping from Speech to Grammar in Early Acquisition,' pp. 187-214. Lawrence Erlbaum Associates, Mahwah, NJ.

Vogel, Ralf (2006). 'Weak Function Word Shift.' Linguistics 44:1059-1093.

- (2009). 'Skandal im Verbkomplex. Betrachtungen zur scheinbar inkorrekten Morphologie in infiniten Verbkomplexen des Deutschen.' Zeitschrift für Sprachwissenschaft 28:307-346.

Wagner, Petra (2000). 'Rhythmical Alternations in German read speech.' In: 'Proceedings of Prosody 2000. Special Session on Intonational Modeling,' pp. $237-245$.

URL: http://pub.uni-bielefeld.de/publication/1917019

Wiese, Richard (1996). The Phonology of German. Clarendon Press, Oxford.

Wurmbrand, Susanne (2006). 'Verb clusters, verb raising, and restructuring.' In: Martin Everaert \& Henk van Riemsdijk (eds.), 'The Blackwell companion to syntax,' pp. 229-343. Blackwell, Oxford. 